\title{
How to Map Audio Data with Students after Doing Fieldwork Using Mobile Devices?
}

\author{
Jérôme STAUB \\ 1IFE-ENS Lyon/France · jerome.staub@gmail.com \\ This contribution was double-blind reviewed as full paper.
}

\begin{abstract}
This paper aims to present a methodological approach to create the sound maps with students. This work is based on several linking themes like sonic geography, sonic mapping and related educational issues. At the crossroads of different themes, it tries to show graphical representations of sounds obtained during fieldwork and it provides mapping choices that help the student map them as legibly as possible. The paper shows how it is possible to introduce sonic geography and sonic cartography into student learning at different levels. It also focuses on relationships between university and school mapping. Educational challenges have arisen in relation to these issues, including the beliefs of students in terms of knowledge and acquisition of skills.
\end{abstract}

\section{Introduction}

By the 1960s, Marshall McLuhan identified three stages in the development of the communication process including the final one called the "Marconi galaxy" or digital age. This transition to the "galaxy" involves passing from a visual culture to an aural one. Sui (2000) echoes this trend by showing how, in the twenty-first century, geographical writings use more aural metaphors when compared with visual metaphors. This is the first clue of a major paradigm shift, in connection with the development of geo-media capabilities. However, geographical approaches did not wait for geo-media development as for instance in the 1900s, GRANÖ produced the first sound maps of the Valosaari Island in eastern Finland. "The aim of this work is to demonstrate that the topic of geographical research is the human environment, understood as the whole complex of phenomena and objects that can be perceived by the senses" (GRANÖ 1929, in CURRIER 2011). To some extent, his position is close to that of Elisée Reclus: "Without being a pure romantic, Reclus was however not least part of a line of minds and sensibilities, while, not objecting in principle to technical innovation or culture, demands a constant recourse to the perception and sensation; who sees in sensory contact with the world [...] an irreplaceable source of knowledge [...]" (CORNUAULT 2008). Today, the possibilities offered by geo-media allow us to envisage a new commentary of sounds and sound maps. They may also have some relevance in educational and teaching approaches of geography. This paper defines a methodology to create sound maps. This methodology is based on two different issues: i) to make the link between sonic geography, sonic cartography and the sonic representations in 
teaching situations, depending on the age of students; and ii) to design a didactic transposition (i.e. the question of the didactic transposition as defined by CHEVALLARD 1985) of the spatial representation of sounds in two different situations (representing sounds during the fieldwork and sonic maps in classroom) (Fig. 1).

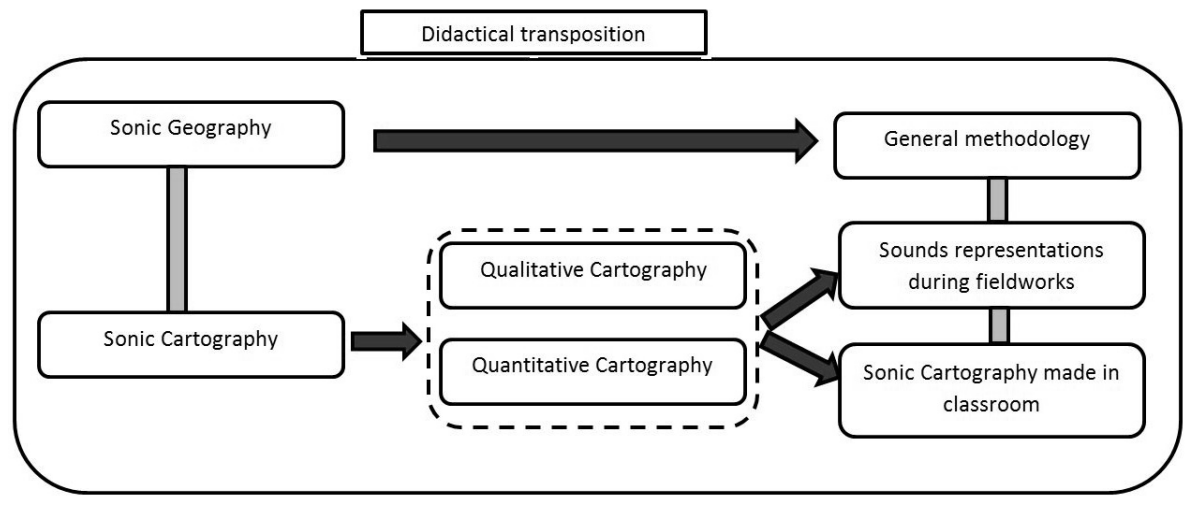

Fig. 1: Didactical transposition (from CHEVALLARD 1985)

\section{Background}

\subsection{Definition of sonic geography}

The relationship between sound and geography is a transdisciplinary topic studied by musicologists as well as architects, sociologists. In light of this diversity, what is specific to sonic geography? The first occurrence of a term for 'sound space' was the creation of the term soundscape by musician Murray Schaeffer. This term borrows the different features of landscape analysis. Associated with the neologism, the Canadian composer conceptualizes sound ecology. Defined as "... the study of the effects of the acoustic environment, or soundscape, on the physical responses or behavioral characteristics of those living within it" (TRUAX 1999, in CURRIER 2011).

Acoustic ecology has become the discipline of study incorporating sound space. However, this description of the soundscape is based on the quality of sound environments offered to listening that must be clear. This observation is followed by a distinction between hi-fi and low-fi environments. Yet, this dichotomy does not apply to ordinary, everyday environmental sounds, such as those in urban areas. This is one of the reasons why the research includes the concepts related to more careful listening and resultant analysis. The notion of sound effect tries to link sound object and soundscape. It is defined as "the manifestation of a phenomenon that accompanies the existence of the object. The effect "is noticeable immediately linked to all the circumstances surrounding the existence of the object" (AUGOYARD \& TORGUE 2005).

Geographical approaches highlighting human perception as a first approach to understanding space combine sociological approaches (like the questionnaire) and more objective analysis (in conjunction with measurements of sound level meters...) (PORTEOUS \& MASTIN 1985). In fact, the geographic scale used is that of the place, containing sound events, in 
agreement with the idea that place is the center of sensory human experiences (Tuan, 1972). This type of sound geography implies working on living spaces, daily scale. The sounds of a place are part of a broader concept: the ambient. They are defined as a "transversal and interdisciplinary concept denoting a situation of sensitive interaction (sensory and signifycant) between the reality [...] and representation [...]" (AMPHOUX 2000). In this sensitive interaction, we discover the sound space.

The sound stage has three characteristics, it is: i) temporal - sound space is in a constant process of renewal; ii) discrete (in the Latin sense of discretum): the sound space is neither continuous nor homogeneous, unlike the visual space, always full and reassuring, it is even less than process of sound recognition which fits the cultural substrata and iii) it has a metabolic character: it means that the sound space has a hierarchy of fluctuating sound, the loudness function and its evolution. These three characteristics of sound space manifest themselves in the form of 'sonic marks', in connection with sound effects. These sonic marks are one of the characteristics of sonic territory (AUGOYARD 1991). It is therefore challenging to define sonic space by virtue of these characteristics. If the notion of sonic marks is valid, it seems appropriate to introduce the concept of a sonic milieu, defined as "the set of material relations between a company and abstract reference and sound milieu" (ROULIER 1999), while remaining in the context of place. This notion of sonic milieu can mix the two key relationships that we have with the sound: noise ratio, designed as a hindrance to quantify and report the sounds in a more sensitive and subjective way. Sonic Geography could be considered as the study of interactions in the sonic milieu. Thus, it is possible to build a first model for understanding simple sonic milieu (Fig. 2).

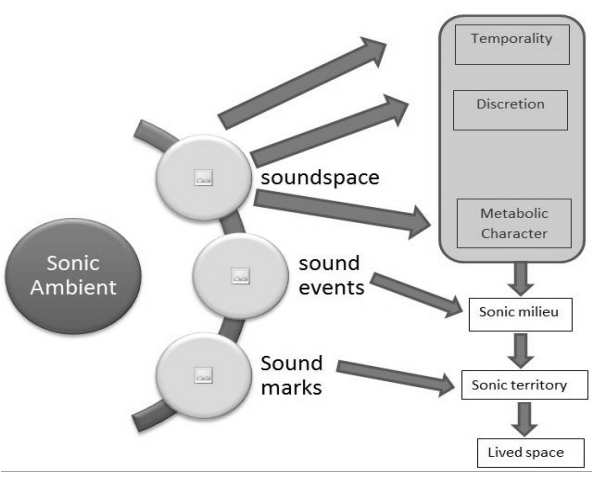

Fig. 2: Geographic Sonic model



Fig. 3: Sonic legend by Krayser

\subsection{Design sonic maps}

Proposing design models for sonic geography cannot be conceived without a clear and direct link with the design of sound mapping and how to represent different components of a sonic milieu. Various attempts to map the sonic spaces have been implemented. However, noise mapping should be differentiated from the mapping of sounds. In the first case, Berlin 
was the first city to propose a noise map in the late 1930s. Since then, many regulations have resulted in the creation of noise maps for local communities. The European directive of 2002 clearly defines how to represent the noise and the need to disseminate it to citizens. This was a first mapping model to respect and adapt to different situations of large cities. It was an institutional quantitative mapping approach showing the noisiest areas, relying on mathematical models. In a second case, more sensitive maps were produced, based on listening to sound and the feeling of participants, often associated with questionnaires (RoULIER 1998). To analyze the sonic space, two types of data are necessary, but often difficult to reconcile. Different elements for graphic semiology of sound qualities have been defined (Fig. 3), but with limited digital application (KRYGIER 1994).

A first sonic GIS (named ChAOS) was designed at the end of the 1990's to graphically represent the different elements of sonic milieu, especially the sound effects (BALAY 1999, 2000). It was a sensitive approach insofar as it was difficult to find a satisfactory symbology while maintaining high legibility on the interactive map. Besides the possibility to integrate different layers by comparing variables like population density, noise levels, occupation of the building, ChAOS offered the opportunity to listen to the recordings made on site (ARNAUD 2001). The results of this work have been defined by BALAY (2003) as choreography.

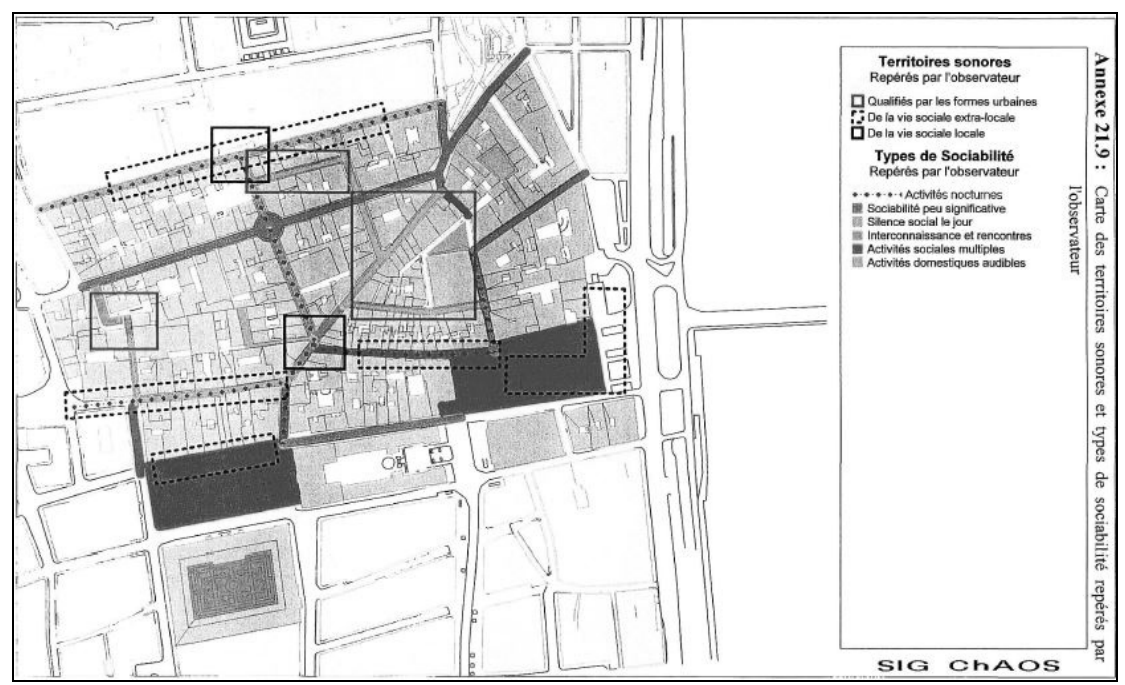

Fig. 4: Sonic territories designed with the GIS ChAOS

According to KRAUSE (2002) and CAGE et al. (2004) a different mapping classification has been designed based on sonic distinctions. Three types of sound events were defined as follows: 'anthropophony' (sounds originating from human activities e.g. voices, traffic sounds), 'biophony' (sounds originating from biological organisms e.g. bird song, dog barking) and 'geophony' (sounds originating from geophysical processes e.g. wave sound) (PAPADIMITRIOUS et al. 2009). Three different maps were based on this qualitative approach, representing the sonic milieu of the lagoon of Antinioti at the northern part of Corfu Island in Greece. 


\subsection{Designing noise maps}

The 2002 EC Directive imposes various structural elements on noise maps. Even if the web applications differed, the eventual mapping forms were quite similar (Fig. 5).

New systems for noise assessment were introduced around citizen participation via mobile phones; the project Noisetube, based on a mobile application, may be an alternative to the citizenship models previously defined. It offers an opportunity for dialogue between local producers of official cartography and citizens around development projects (D'HONDT et al. 2012). This system relies on sound recordings from a microphone laptop and uses the GPS for geotagging. A KMZ file is generated and viewable in a virtual world. Research conducted in Brussels used other visualization systems (Fig. 5).

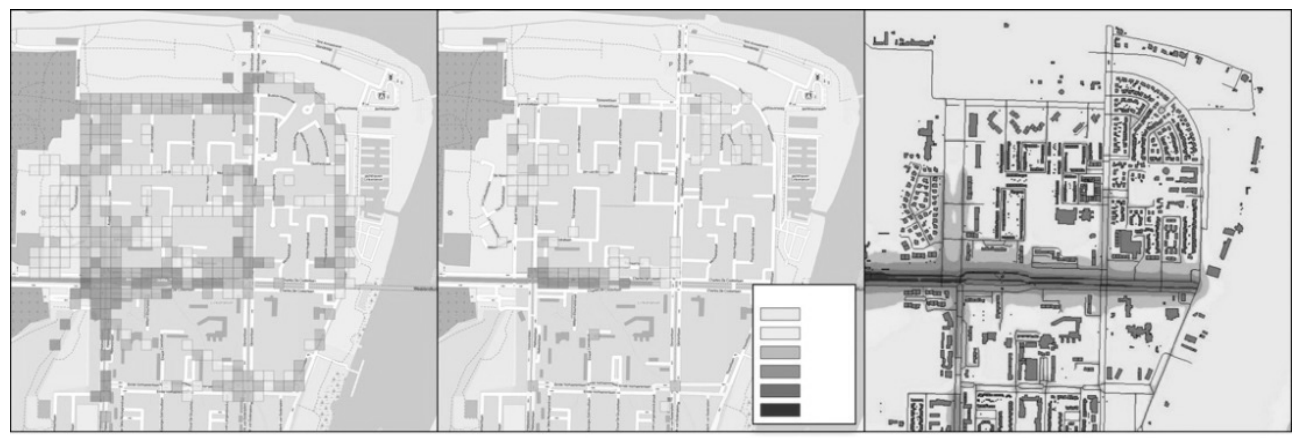

Fig. 5: $\quad$ Noise Tube maps in Brussels (D’HondLT et al. 2012)

\section{Empirical and Mixed Methodology in an Attempt to Perceive the Sonic Milieu}

To collect the sonic milieu of students, a mixed methodology (quantitative and qualitative), based on the use of mobile phones has been developed in conjunction with the elements of a geographic sonic analysis. It involves four steps.

\subsection{Pre-experiences to the fieldwork}

The first approach was inspired by the pre-virtual experience in a thesis devoted to neogegraphy (VALENTIN 2010). This pre-experience refers to the idea that sounds are recognized as being based on a cultural sonic substrate, the result of our past experiences (from the discrete nature of the acoustic space, see 1.2). Several pre-experiments are possible, depending on the area being studied. If space is visited on a near daily basis, students can indicate the sounds they expect to hear from the journey. Conversely, if a space is little known or unknown, students may immerse themselves in a virtual world and thanks to panoramic photographs, they could describe the sounds they think they might hear. By comparison with the sounds heard during fieldwork, the pre-experiment aims to show that auditory perception depends strongly on the students' sound memory. 


\subsection{Collecting data during fieldwork}

The second step is to move along the path determined for the fieldwork, which corresponds to different types of space. Data collection can be organized around specific locations. Students are divided into groups of four and they criss-cross the space (Fig. 6). Each student in the group has a particular mission. With the help of various mobile devices and their ears, they try to understand and record the sound environment in which they are the centered. Four tasks are assigned to them: i) collecting noise levels, ii) location and the identification of types of noise, iii) localization and determination of perceived loudness and iv) collection of sound recordings.
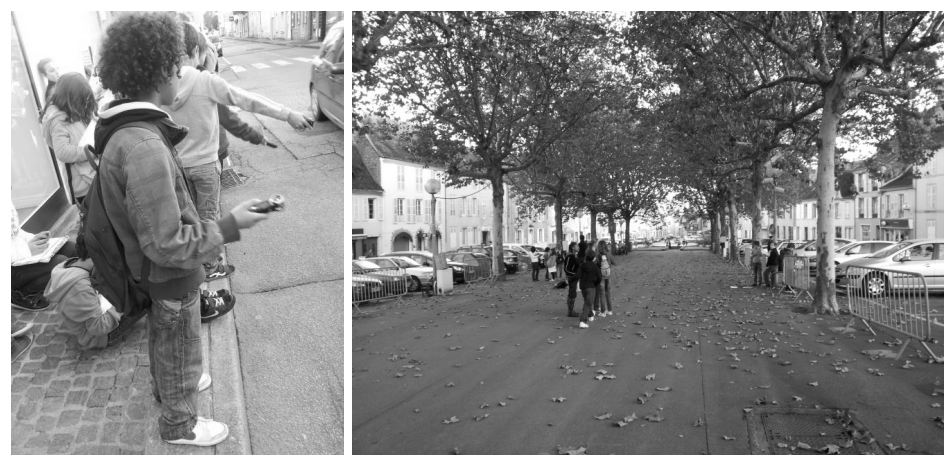

Fig. 6: Student collecting sound data (left) \& distribution group to capture the sound environment (right)

Different digital collections can be tabulated or graphically represented in spatial terms. These representations incorporate the precepts established previously (see 1.1): the importance of the temporal context (date, hour) for the determination of two spaces of sound diffusion (near and far). For sensed intensity, determination in one of five categories matches the possibilities of students in accordance with the questionnaires distributed by $\mathrm{NPPE}^{1}$. A digital version for website is in process (Fig. 7).
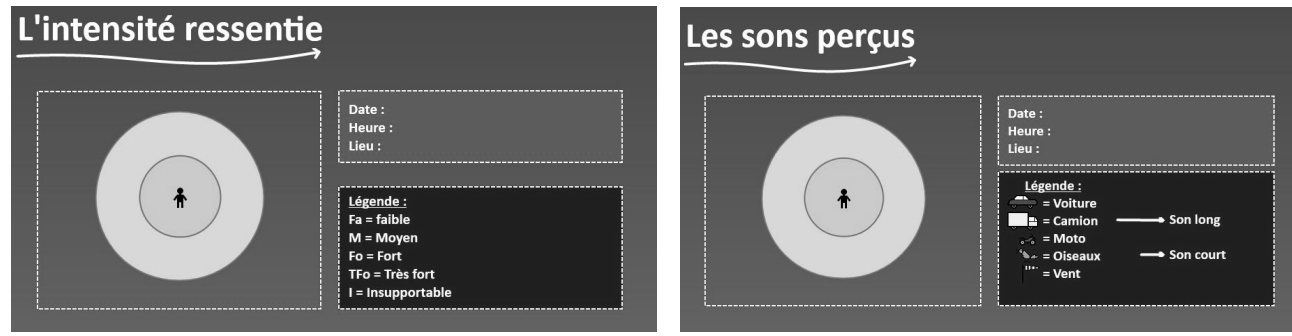

Fig. 7: First web design of sensed intensity (left) \& First web design of sound perception (right)

1 Noise Prevention Plan in the Environment. This document is the second step after the publication of noise maps from citizens (according to the European Directive 2002); many of these NPPE are based on some questionnaires about local noise intensity felt by people. 
We had the opportunity to test NoiseTube but it was too difficult to implement for several reasons: it requires good wifi connectivity and it was difficult to properly calibrate a wide range of mobile phones. NoiseTube was difficult to use and to repeatedly optimize during longer journeys (Fig. 8).

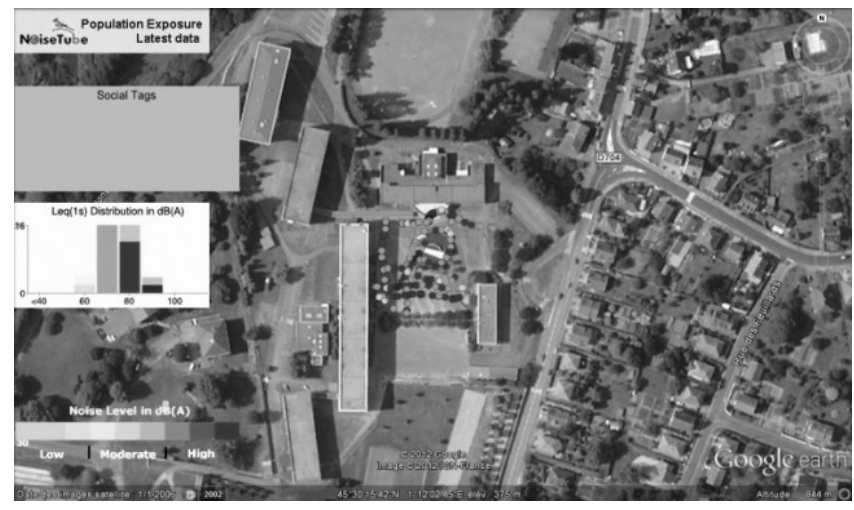

Fig. 8:

Noise tube experimentation in a playground

\subsection{Mapping data}

The representation of sounds on a map with the students fits most approaches to sound mapping defined above (1.2). We chose to use ArcGIS Explorer Online to create and share the sonic maps. This choice was based on the possibility offered by this web mapping tool to make students use ArcGIS Desktop and collaborate through ArcGIS Online.

The four indicators may lead to the first four maps of data to analyze. Then these four maps can be synthesized according to the data. Finally, it may be possible to produce a combined map, representing all the data.
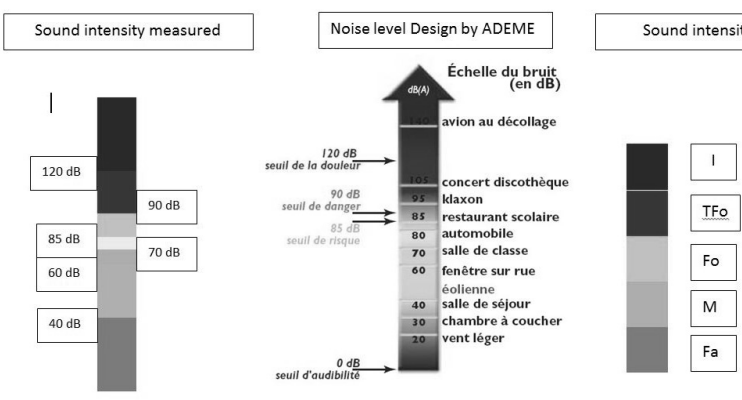

Fig. 9:

Different representations of sound intensity

Choosing elements for the representation is challenging. The notion of sound mark has a direct link with graphic semiology used in web mapping. In fact, in webmapping, the thumbtack will gradually replace the point with the aim of representing a brand in the digital space to locate information in the bubbles. This was the first graphical element used to map sound events and create the first four maps. Similarly, the colors on the loudness match those used by ADEME (an environmental organization). They were simplified to characterize the intensity felt as five prime colors (Fig. 9). Similary, in accordance with 
ChAOS GIS, all the recordings were made available for playback. Due to this multimedia addition, the form of the thumbtack was changed to represent a listening point (example in Fig. 10). Noise types and descriptions were assigned to maps, introducing them in text form so they could possibly be re-used in other studies or courses.

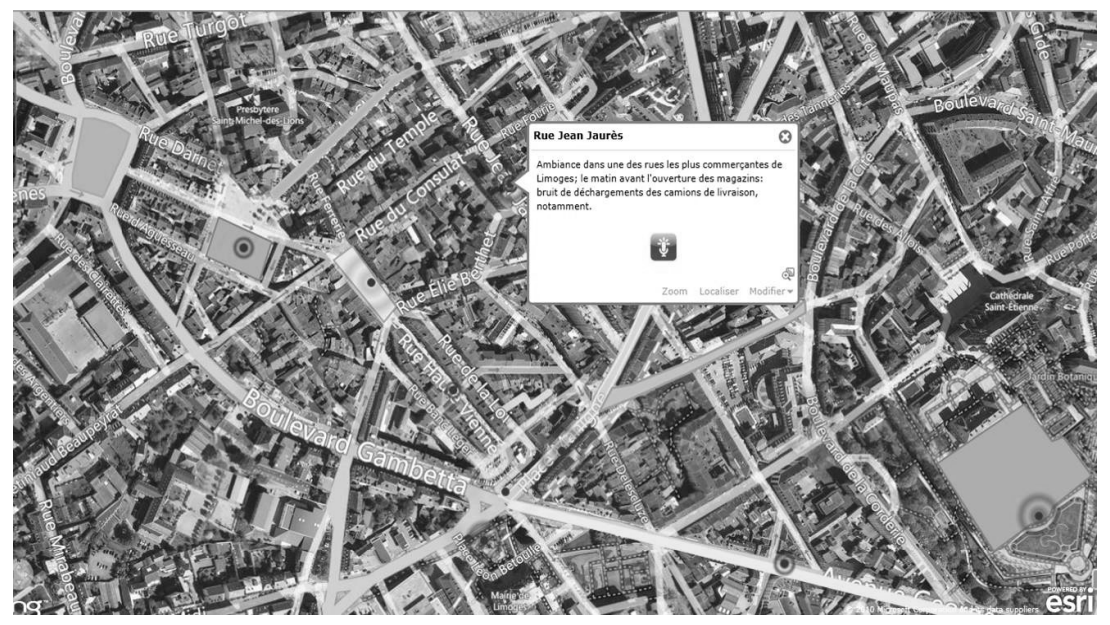

Fig. 10: Mapping sonic milieu

\section{$4 \quad$ Learning Situations with Sounds and Educational Research Perspectives}

\subsection{Sonic geography in educational curriculum}

Several pilot experiments have been carried out over the past three years, on different age groups in primary schools, secondary and high schools (STAUB \& SANCHEZ 2012). However, the full methodology has been implemented this year, through fieldwork with students aged 11 years old. This work was a part of the geography curriculum topic entitled "live near space" highlighting the importance of local fieldwork. In this instance, the sound recordings may be an approach that presents near space. In this perspective, two fieldwork visits were made by two different classes at different times of the day. In the first part of the methodology, only the sounds previously heard by students were selected because the near space was fully known by them. However, mapping was much more difficult because of the age of the students who had no experience in web mapping. In fact, though the hypotheses were designed by the students, most maps had to be produced by the teacher and discussed with students after.

One of the most striking elements of mapping soundscapes was the surprise, sometimes the perplexity in students' faces, of the results they obtained, which alters their relation to learning and knowledge. Another reason for this reaction was that the approach puts into perspective a complex situation. The importance of the contribution of the teacher was crucial to get the students involved in the process. Student motivation, especially the youngest, was often the result of the contribution of the teacher. One of the objectives was 
to highlight how understanding about space can be assessed in this type of teaching situation. To determine these capabilities, we allude to the learning objectives in the French history and geography curriculum handbook. This handbook defines seven types of capacity: locating and situating, describing, explaining, recounting, reading and practicing different languages, taking a critical look and exercising judgment, designing a sketch.

\subsection{Links and perspectives with research in education}

Sonic mapping fits directly into a socio-constructivist approach of learning in which students construct their knowledge from fieldwork, in a collaborative manner. It also relies on the concept of instrumental mediation of Vygotski and instrumental genesis suggested by Rabardel. They consider the instrument (here, mainly mobile phones) as a construction and a mediator for the materiality of the fieldwork, to yourself and to others (SANCHEZ 2007). This notion of mediation is also found in the patterns of SHARPLES et al. (2010). This work also questions the students' personal epistemology in their reports about the knowledge and beliefs about learning. PERRY's model (1970), synthesized by MoOrE (2002) can be used: it defines different positions in the learning experiences of students: "Dualism (positions 1 and 2) knowledge is considered as true or false and the teacher is the person who transmits truths. The multiplicity (positions 3 and 4): This category begins with the modification of dualism when the person realizes and accepts the existence of unresolved issues. However, it considers that this situation is temporary and that eventually; the truth is accessible; because the truth is still considered as the ultimate goal of the research. In position 4 , we can observe that students will consider issues for which there is no solution, there is no non-arbitrary basis on which they can be based: then all views are valid, and everyone has the right to have their own ideas. The contextual relativism (position 5): where knowledge is seen as contingent and provisional because it depends on the context of thinking that has arisen. The transition from position 4 to position 5 is marked by the awareness of the individual learning process which requires choosing one's own point of view. Personal commitment in relativism (positions 6-9): for Perry, the transition to position 6 is that of intellectual considerations to legal, that is to say for affirmation of self, identity, values, and ambitions" (KRAMAR 2012). At first, we will try to evaluate in which posture the students are. A more quantitative approach will be necessary to validate this first approach. Didactic transposition is also a central point in the relations between sonic geography and educational situations. Introducing sounds and noise in studying geography is part of an innovative approach and must be based on sonic geography in order to validate the educational approach.

\section{Conclusion}

Different aspects of sonic geography were highlighted in this work. Besides attempting to synthesize the concept, this article also aims to show the many aspects of sonic mapping. One of the objectives is also to create a constant dialogue with the learning process of space through sound in its many definitions. This dialogue is far from giving us the full extent of its wealth. This study can be considered in relation to many other aspects. It would for example be interesting to show how this approach could be carried out with students using a VGI (Volunteered Geographic Information approach (GOODCHILD 2007), where crowd- 
sourcing is used. To paraphrase the formula "citizens as sensors", could we not speak of "students as sensors"? In fact, the previous acronym could be turned into VGIE (Volunteered Geographic Information for Education).

\section{References}

Amphoux, P. (2000), Ambiance architecturale et urbain. In: LÉVy, J. \& LuSSAUlT, M. (Eds.), Dictionnaire de la géographie et des sciences de l'espace social. Paris, Editions Belin.

ARLAUD, B. (2001), Vers une infographie de l'ambiance sonore urbaine. Thèse de doctorat CRESSON, Université de Nantes, Ecole d'architecture de Grenoble, UMR 1563, Vol. 1 $\& 2,384 \mathrm{p}$.

AugOyard, J. (1991), Les qualités sonores de la territorialité humaine. Architecture \& comportement, 7 (1).

Augoyard, J. \& Torgue, H. (Eds.) (1998), A l'écoute de l'environnement: répertoires des effets sonores. Marseille, Parenthèses.

BALAŸ, O. (1998), SIG ChAOS, La représentation de l'environnement sonore à l'aide d'un système d'information géographique. Lyon prépare son observatoire de l'environnement sonore. Annales des ponts et chaussées, 88 (Observatoires locaux), 61-66.

BALAŸ, O. (1999), SIG ChAOS, La représentation de l'environnement sonore à l'aide d'un système d'information géographique. Lyon, Grenoble, 62 p.

BALAŸ, O. (2003), Les chorographies de l'urbanité sonore. Géocarrefour [En ligne], 78/2. http://geocarrefour.revues.org/253

Cage, S., Ummadi, P., Shortridge, A., QI, J. \& Jella, P. K. (2004), Using GIS to develop a network of acoustic environmental sensors. In: Proc. ESRI International User Conference, Aug 9-13, San Diego, CA, USA, 15-28.

ChÉTELAT, J. (2009), La Fig.uration cartographique de l'espace sonore [Electronic Version]. Images Revues. http://imagesrevues.revues.org/437 (January 2012).

Chevallard, Y. (1985), La transposition didactique, du savoir savant au savoir enseigné. Grenoble, La Pensée Sauvage.

Cornuault, J. (2008), Elisée Reclus, six études en géographie sensible. Paris, Isolato.

CURrIER, K. E. (2011), Auditory Representation in Spatial Applications. A Thesis submitted in partial satisfaction of the requirements for the degree Master of Arts in Geography, University of California. geog.ucsb.edu/ currier/files/currier_2011.pdf.

D’HondT, E., Stevens, M. \& JACOBS, A., (2012), Participatory noise mapping works! An evaluation of participatory sensing as an alternative to standard techniques for environmental monitoring, Pervasive and Mobile Computing (2012). doi: 10.1016/j.mcj.2012.09.002

GrANÖ, J. (1929), Reine geographie. Acta Geographica, 2, 1-202.

Kent, M., Gilbertson, D. \& Hunt, C. (1997), Fieldwork in Geography Teaching: A critical review of the literature and approaches. Journal of Geography in Higher Education, 21 (3), 313-332.

KrAmAR, N. (2012), Apport d'un jeu sérieux pour l'instauration d'un nouveau rapport au savoir du point de vue épistémologique: cas du jeu Clim@ction, Mémoire de Master 2ème année Histoire Philosophie et Didactique des Sciences, On-line, IFE-ENS Lyon. 
KRAUSE, B. L. (2002), Wild soundscapes in the national parks: an educational program guide to listening and recording, National Park Service, USA.

Krieger, J. (1994), Sound and Geographic Visualisations. In: MAcEACHrEn, A. \& TAYLOR, V. (Eds.), Visualization in Modern Cartography. Oxford, Pergamon, 149-166.

MOORE, W. (2002), Understanding learning in a postmodern world: reconsidering the perry scheme of intellectual and ethical development. In: Hofer, B. K. \& PINTRICH, P. R. (Eds.), Personal epistemology: The psychology of beliefs about knowledge and knowing chapter Personal epistemology as a psychological and educational construct: An introduction. Lawrence Erlbaum Associates Publishers, 17-36.

Papadimitriou, K. D., Antonios, D. M., Athanasios, S., Kallimanis, A. S. \& Pantis, J. D., (2009), Cartographic Representation of the Sonic Environment. The Cartographic Journal, 46 (2), 126-135.

PERRY, W. G. (1970), Forms of ethical and intellectual development. New York, Rinehart and Winston.

Porteous, J. \& MAstin, J. (1985), SoundScape. Journal of Architectural Planning Research, 2, 169-186.

RouliER F. (1998), Le milieu sonore d'Angers. Essai d'une géographie du bruit. Geography thesis, 434 p., 80 cartes. Angers.

RouliER, F. (1999), Pour une géographie des milieux sonores. http://cybergeo.revues.org/5034 (January 2012).

SANCHEZ, E. (2007), Investigation scientifique et modélisation pour l'enseignement des sciences de la Terre, contribution à l'étude de la place des technologies numériques dans la conduite d'une classe de terrain au lycée. Thèse de doctorat. Université de Lyon. http://tel.archives-ouvertes.fr/tel-00199077/fr/.

SANCHEZ, E. (2008), Integrating Geomatics into the Curriculum: Inquiry-Based-Learning during a Fieldwork Course. In: Jekel, T., Koller, A. \& DONERT, K. (Eds.), Learning with Geoinformation III. Heidelberg, Wichmann, 78-87.

SCHAFFER, R. (2010), Le paysage sonore, Le monde comme musique. Paris, Wildproject.

Sharples, M., TAYLOR, J. \& GiASEMI, V. (2010), A theory of learning for the mobile age: learning through conversation and exploration across contexts. In: BACHMAIR, B. (Ed.), Medienbildung in neuen Kulturräumen: die deutschprachige und britische Diskussion. Wiesbaden, VS Verlag für Sozialwissenschaften, 87-99.

Schiewe, J. \& Kornfeld, A.-L. (2009), Framework and Potential Implementations of Urban Sound Cartography. Advances in GIScience, 1.

Staub, J. \& SANCHEZ, E. (2012), Mapping Space through Sounds and Noises with Digital Mobile Devices in School: An Innovative Approach for Geography Education. In: JEKEL, T. et al. (Eds.), GI_Forum 2012. Berlin/Offenbach, Wichmann, 193-203.

SuI, D. (2000), Visuality, Aurality, and Shifting Metaphors of Geographical Thought in the Late Twentieth Century. Annals of the Association of American Geographers, 90 (2).

TRUAX, B. (1999), Handbook for acoustic ecology. 2nd edition. http://www.sfu.ca/sonic-studio/handbook/.

TUAN, Y.-F. (1972), Space and Place: the Perspectives of Experience. Minneapolis, Univ. of Minnesota Press.

VALENTIN, J. (2010), Usages géographiques du cyberespace: nouvelle appropriation de l'espace et l'essor d'une "néogéographie". Geography thesis. 